\title{
¿El marxismo se comporta como un Programa de Investigación Científica? Propuesta de adaptación de la metodología de Lakatos.
}

\author{
Is Marxism a sort of Scientific Research Programme? A Proposal for the Adaptation of \\ Lakatos's Methodology to the History of Marxism.
}

Carlos Maximiliano Macías Fernández

Resumen: Los continuadores de Marx y Engels heredaron un cuerpo doctrinal básico que fue desarrollado hasta constituirse en una tradición política. Los discípulos elaboraron diversas teorías regionales de alcance medio para atender las cuestiones tácticas y estratégicas que el movimiento fue enfrentando. En paralelo, debían explicarse $-y$ sin contradecir las tesis más elementales de los fundadores - las anomalías surgidas en el dominio de la experiencia política cuando pareciesen refutar las previsiones originales. El artículo propone que se dan las condiciones para considerar el desarrollo del marxismo desde la metodología que el filósofo de la ciencia Imre Lakatos propuso para la reconstrucción racional de la ciencia. Como en todo Programa de Investigación, para los clásicos el marxismo también constaba de una «heurística positiva» y otra «heurística negativa». Se recurren a algunos ejemplos de debates clásicos en los que la metodología de Lakatos tiene la virtud de explicar etiquetas recurrentes en esta tradición - tales como el dogmatismo, la ortodoxia, las heterodoxias o el revisionismo - como posiciones coherentes al examinarlas en relación con el «núcleo» del programa marxista y sus aplicaciones prácticas. Como conclusión, se especifican las condiciones para una adaptación reflexionada y controlada de la propuesta de Lakatos a las peculiaridades del marxismo. La pertinencia de esta adaptación se demuestra en su capacidad para hacer comprensibles las controversias dentro del marxismo como combinaciones de argumentos teóricos y resultados prácticos.

Palabras clave: Historiografía del marxismo; Epistemología marxista; Controversias marxistas; Metodología de los Programas de Investigación Científica; Imre Lakatos.

Abstract: Those who continued the political tradition founded by Marx and Engels inherited just a basic body of doctrine. The disciples had to develop different theories of middle range

\footnotetext{
* Español, magíster en Política Comparada por el Instituto de Estudios Políticos de París (Francia) y doctor en Geografía por la Universidad Estatal Paulista (UNESP), campus de Presidente Prudente (São Paulo, Brasil). Profesor en el Doctorado en Ciencias Sociales, Infancia y Juventud del Centro de Estudios Avanzados en Niñez y Juventud (Manizales, Colombia). Este artículo deriva de un proyecto financiado por la Fundação de Amparao á Pesquisa do Estado de São Paulo (FAPESP), con el título «O processo de transnacionalização dos movimentos socioterritoriais: estudo das transterritorialidades da Via Campesina sobre as proposições de agroecologia e Soberania Alimentar no Confronto Político», proceso 2014/251342 para el periodo 01/07/2015 a 31/03/2018, bajo la dirección del Dr. Bernardo Mançano Fernandes. Correo electrónico: carlosmaxmf@gmail.com
} 
to address the tactical and strategic issues faced by the movement. Meanwhile, the arising anomalies in the domain of political struggle had to be solved whenever they seemed to refute the original predictions from the founding fathers. This article suggests that it might be useful to consider the development of Marxism with the methodology proposed by the philosopher of science Imre Lakatos for the rational reconstruction of science. As in any Research Program, for the classics of Marxism their project counted with a "positive heuristic" and a "negative heuristic." Some examples of classical debates are intended to show how Lakatos's methodology has the virtue of explaining recurring labels within this tradition such as dogmatism, orthodoxy, heterodoxy or revisionism - as coherent positions when examined in relation to both the "core" of the Marxist program and its practical applications. In conclusion, the conditions for a critical and controlled adaptation of Lakatos's methodology to the peculiarities of Marxism are specified. The relevance of this adaptation is convincing thanks to its ability to make controversies within Marxism understandable as combinations of theoretical arguments and practical results.

Keywords: Historiography of Marxism; Marxist Epistemology; Marxist Controversies; Methodology of Scientific Research Programmes; Imre Lakatos.

Recibido: 25 marzo 2019 Aceptado: 4 agosto 2019

\section{Introducción.}

\section{La retórica popperiana en las controversias teóricas del marxismo.}

Las controversias teóricas del marxismo a menudo se han presentado bajo una retórica popperiana. Tomemos como ejemplo una de las primeras críticas que se dirigieron a El Capital de Marx por haber fallado en sus predicciones. Su autor fue un antiguo socialista, el economista y sociólogo alemán Werner Sombart (1863-1941). Más tarde, Trotsky le recoge el guante y trata de desmentirlo.

En 1939 Trotsky ${ }^{1}$ enumeraba las diferentes predicciones fallidas que Sombart indicó en El capitalismo moderno, publicado cuatro décadas antes, en 1902. Las predicciones fallidas habrían sido fundamentalmente tres: el empobrecimiento o pauperización absoluta de la clase obrera; la concentración de capital, con la consiguiente desaparición de todas las clases con la excepción de capitalistas y proletarios; y el necesario colapso económico del capitalismo. Muy lejos de cumplirse, Sombart consideraba evidente que el capitalismo se había convertido en un sistema estable y relativamente armonioso. Trotsky no tuvo problemas para enfrentar estas críticas con el objetivo de desmentirlas, mostrando que cada una de ellas se había cumplido para entonces o, por lo menos, estaba muy cerca de hacerlo.

Tanto Trotsky como Sombart parecen coincidir con la interpretación que el filósofo de la ciencia Karl Popper tenía del papel que debían jugar las predicciones científicas. Al

1 Trotsky, Leon, El pensamiento vivo de Karl Marx, Buenos Aires, Editorial Losada, 1943. 
falsacionismo - nombre por el que se conoció la propuesta de Popper $^{2}$ - no le interesa la coherencia interna de un sistema categorial como el de El Capital, sino su capacidad para realizar predicciones que resulten falsables, es decir, que pudieran demostrarse como falsas si el resultado predicho no se cumple. El contenido en sí de la teoría o la manera en la que llegue a plantearse carecen de importancia. La labor de todo científico consistiría en proponer un desarrollo de los acontecimientos que pudiese ser contrastado empíricamente. Si cualquier posible desenlace de los acontecimientos sirviese para confirmar la teoría, entonces ésta carece de interés y no debe ser considerada científica. Si los acontecimientos no corroborasen sus previsiones, quedaría demostrada la insuficiencia de la teoría examinada y, en consecuencia, surgiría la necesidad de sustituirlo por otra teoría que, por el momento, no hubiera sido desmentida por la fuerza de los hechos. De esa manera, se irían desechando las teorías que no se sostuvieran ante la realidad y se mantendrían aquellas que mejor predicen acontecimientos.

Tanto Sombart como Trotsky consideraban que la teoría del otro había sido falsada por la historia, siendo eso una prueba suficiente de la necesidad de desecharla. Como Sombart consideraba falsada la propuesta teórica de Marx, se propuso proporcionar una interpretación teórica alternativa del capitalismo compatible con el curso de la historia. Por su parte, Trotsky, restituyó a Marx frente a Sombart, después de comprobar que los hechos finalmente le daban la razón.

La perspectiva de Popper nos lleva a una inevitable paradoja al pretender aplicarla a cualquier tipo de pensamiento social: sostener que Trotsky tenía razón en 1939 no equivale a sostener que Sombart se equivocase en 1902. Popper estaba pensando en científicos que se enfrentasen a una misma realidad o, cuanto menos, reproducible en las mismas condiciones. Pero Trotsky y Sombart estaban considerando experiencias históricas diferentes.

El problema, aquí, no tiene su causa en Popper sino en Trotsky y Sombart, que asumieron un falsacionismo avant la lettre en un ámbito en el que no tiene ningún sentido. Para el pensamiento político, su campo de experimentación no es el ambiente controlado de un laboratorio, sino su propia realidad históricamente determinada. Sombart publicó años antes de que estallara la Primera Guerra Mundial, y décadas antes de que una barbarie como el nazismo fuese imaginable. Trotsky le replicó casi cuatro décadas después, tras haber vivido sucesos como la Primera Guerra Mundial, la Revolución rusa, la crisis de 1929, el New Deal de Roosevelt y el ascenso del fascismo en Europa. Por si fuera poco, Trotsky también podía vislumbrar en un futuro muy cercano una nueva guerra mundial que estaba dando sus primeros pasos con la anexión de Hitler de Austria y la invasión de Checoslovaquia. Cada uno en su momento tenía a la realidad de su lado. Pero, con el tiempo, cada uno se veía desmentido por ella.

Este ejemplo muestra que el falsacionismo de Popper es insuficiente para comprender cómo los teóricos sociales discuten sus propuestas, porque el campo de la experiencia histórica puede en algunas ocasiones desmentir y en otras corresponder con unas predicciones. Si bien Trotsky podía contar con elementos más que sobrados en 1939 para argumentar que el capitalismo era inestable - falsando así la hipótesis de Sombart_, es

2 Popper, Karl, La lógica de la investigación científica, Madrid, Edición Tecnos, 1980. 
muy cuestionable que hubiera logrado demostrarlo con la misma contundencia en 1902, cuando el viento histórico soplaba por la popa de su contrincante. Es más, si Trotsky hubiera ido más allá de la retórica y se hubiese comportado como un coherente popperiano, nunca debería haberse iniciado en el marxismo a finales del S.XIX, cuando la experiencia daba la razón a Sombart. Sin embargo, Trotsky y muchos otros mantuvieron un compromiso con las ideas de Marx a pesar de la distancia cada vez mayor que durante décadas separó a la teoría marxista de la realidad política. Pero, al mantenerse fiel a esta tradición de pensamiento, Trotsky pudo esperar hasta un momento posterior en el que el curso de los acontecimientos, ahora sí, devolvía la razón a Marx, y se desmentía a Sombart.

Para nosotros, no se trata de zanjar cuál de los dos tenía razón sino de comprender cuál es la lógica que está detrás de las controversias que, como nos muestra la experiencia, no se corresponde a la ciencia tal como la entendía Popper. Pero Popper mismo desestimó este problema. Su perspectiva era más normativa que explicativa, y consideró que quien continuaba sosteniendo una teoría a pesar de la evidencia empírica contraria se situaba fuera de la tradición científica. Popper se cuidó de atacar directamente a Marx, al que consideraba un buen hombre que había hecho previsiones que resultaron falsadas por los hechos. Otra cosa eran los marxistas, que no podían «abrir un periódico sin hallar en cada página pruebas confirmatorias de su interpretación de la historia»3.

Sin embargo, fue Popper el que se encontró con un problema ya que, a lo largo de la historia de la ciencia, el aferrarse a unos principios a pesar de la evidencia empírica negativa no fue algo exclusivo de dogmáticos marxistas. Este comportamiento resulta más la norma que la excepción en cualquier disciplina, por lo que su modelo interpretativo de la ciencia se veía, él mismo, desmentido por la experiencia histórica. Parecía razonable, por tanto, evitar modelos como el de Popper que no correspondiesen con la manera en la que efectivamente actúan los científicos.

Este fue el razonamiento que llevó a un cercano colaborador de Popper, el húngaro Imre Lakatos, a elaborar una propuesta alternativa -o mejorada - del falsacionismo. Su propuesta se formalizó en 1965 como la metodología de los Programas de Investigación Científica ${ }^{4}$, con el objetivo de reconstruir racionalmente el proceso por el que los científicos desarrollan sus propuestas, asumiendo que durante algunos periodos de tiempo más o menos largos una comunidad científica puede mantener sus postulados a pesar de nadar en medio de «un océano de anomalías» que los cuestionasen. Esto resulta especialmente interesante para explicar el ejemplo de Trotsky. Si bien las controversias pueden adoptar una retórica popperiana, la práctica real de los teóricos no se corresponde con ella, ya que son capaces de soportar las evidencias contrarias durante largos periodos antes de llegar a cuestionarse las piedras angulares de su postura.

Para solventar este problema, Lakatos tuvo que ir más allá de Popper y asumir algunas ideas ajenas a su maestro ya avanzadas por Norwood R. Hanson ${ }^{5}$ y popularizadas

3 Popper, Karl, Conjeturas y refutaciones: el desarrollo del conocimiento científico, Barcelona, Paidós, $1983,62$.

4 Lakatos, Imre, La metodología de los programas de investigación científica, Madrid, Alianza Editorial, 1989.

${ }_{5}^{5}$ Hanson, Norwood R., Patterns of Discovery: An Inquiry into the Conceptual Foundations of Science, Cambridge, Cambridge University Press, 1958. 
desde 1962 por Thomas Kuhn' ${ }^{6}$. Desde entonces, existe el consenso de que la ciencia necesita partir de una base metafísica, indemostrable y, por eso, irrefutable. El científico se adscribe a ella por motivos más próximos a la fe que a la razón. Esto ya había sido adelantado, al menos, desde trabajos como los de Ludwig Fleck en $1935^{7}$ o Alexander Koyré en 19398, antecedentes de la propuesta kuhniana de los paradigmas. Desde el marxismo, a mediados de los 50 el rumano Lucien Goldmann, discípulo de Lukács, recurría a la «apuesta»9, definida como esa fe que toda ciencia debe tener cuando se lanza en la construcción de su objeto, del cual no puede estar segura hasta que el proceso de construcción no haya sido completamente dominado y su demostración se realice desde sus propios criterios de validación. Todo conocimiento científico parte así de una apuesta, de una incertidumbre que, en el caso de un pensamiento social, acaba demostrando su pertinencia en un desarrollo histórico ulterior. Lakatos no era ajeno a ninguna de estas tradiciones ${ }^{10}$.

Lakatos tradujo estos debates en la propuesta de que la ciencia no progresa aisladamente en teorías individuales que se contrastan aisladamente, sino como conjuntos de teorías a los que denominó Programas de Investigación Científica (PIC). Cada PIC se fundan a partir de un «núcleo firme» compuesto por las asunciones y postulados más básicos y generales; esa apuesta que, necesariamente, se plantea en términos ambiguos, sin pretensiones de ser contrastada empírica e inmediatamente. A partir de la concepción general del «núcleo» se derivarán hipótesis empíricamente contrastables (una heurística positiva), que permiten el desarrollo del PIC en teorías científicas coherentes de rango medio que pueden dirigirse a cuestiones muy variadas. Pero, por su propia naturaleza, resulta necesario proteger al «núcleo» de cualquier contrastación empírica directa que pudiera contradecirlo. Esto lleva a los científicos a levantar un «cinturón protector» de hipótesis auxiliares (una heurística negativa) que mantiene al núcleo incuestionado. La salud de un PIC viene dada por la relación entre estas dos heurísticas. Siempre que un PIC solvente con éxito las anomalías con las que necesariamente acaba por encontrarse $\mathrm{y}$, además, desarrolle nuevas predicciones experimentales, estaríamos ante un PIC progresivo, es decir, exitoso. Por el contrario, cuando los teóricos caen en una posición defensiva en la que la mayor parte de sus esfuerzos se dirige a intentar refutar las constantes anomalías que cuestionan el «núcleo firme», perdiendo así la capacidad de realizar nuevas predicciones exitosas, estaríamos ante un PIC regresivo, es decir, en decadencia.

\footnotetext{
${ }^{6}$ Kuhn, Thomas S., La estructura de las revoluciones científicas, Madrid, Fondo de Cultura Económica, 2001.

7 Fleck, Ludwik, La génesis y el desarrollo de un hecho científico, Madrid, Alianza Editorial, 1986.

8 Koyré, Alexandre, Estudios galileanos, Madrid, Siglo XXI, 1980.

9 Goldmann, Lucien, El hombre y lo absoluto, Barcelona, Península, 1968.

10 Lakatos mismo había conocido bien el marxismo en Hungría. En las últimas dos décadas, diferentes publicaciones han explicado con detalle su pasado comunista y la herencia perdurable del marxismo hegeliano. Véase Long, Jancis, "Lakatos in Hungary", Philosophy of the Social Sciences 28:2, 1998, 244-311; Kadvany, John, Imre Lakatos and the Guises of Reason, Londres, Duke University Press, 2001; Ropolyi, Laszlo, "Lukács and Lakatos", Kampis, György, Kvasz, Ladislav, Stoeltzner, Michael (eds.), Appraising Lakatos, Londres, Springer, 2002, 303-338; Bandy, Alex, Chocolate and Chess. Unlocking Lakatos, Budapest, Akadémiai Kiadó, 2010; Dusek, Val, "Lakatos between Marxism and the Hungarian Heuristic Tradition", Studies in East European Thought 67:1, 2015, 61-73.
} 
Nuestro objetivo será demostrar que la metodología de Lakatos es una herramienta enriquecedora para reconstruir una tradición de pensamiento político como el marxismo. Para ello, deberemos precisar de qué manera el marxismo se comporta como un PIC, lo que nos permitirá discutir los términos en los que es posible plantear la adaptación de Lakatos a una tradición de pensamiento que, en rigor, no corresponde a una ciencia experimental convencional. En la primera parte del artículo se discuten dos tentativas previas que han intentado reconstruir el marxismo desde esta metodología. Al señalar sus limitaciones será más fácil avanzar hacia una adecuada adaptación. A continuación, recurriremos a algunos ejemplos concretos que muestran cómo los clásicos del marxismo consideraban su propia praxis teórica y política como una especie de PIC, haciendo énfasis en el carácter específico de la relación entre teoría y praxis. El breve repaso que haremos a algunos aportes de Gramsci, Luxemburgo, Kautsky y Marx no es, en sí, la aplicación de la adaptación propuesta de la metodología de Lakatos a ninguna controversia específica del marxismo sino, simplemente, una muestra de que los protagonistas de su historia pensaron en unos términos muy similares a la adaptación que aquí proponemos. En las conclusiones, pasaremos a sistematizar las condiciones de una adaptación de esta metodología a la historia de las controversias en el marxismo que permita aprovechar su potencial heurístico para futuras investigaciones.

\section{Las limitaciones en la adopción de la metodología de Lakatos por Burawoy y Callinicos.}

A Lakatos le parecía evidente que el marxismo era un PIC, pero uno que no tenía mayor interés que el de ser un excelente ejemplo de PIC regresivo, ofuscado en buscar hipótesis ad hoc para protegerse ${ }^{11}$. En esto, Lakatos continuó con la costumbre de Popper de asociar al marxismo con el psicoanálisis, catalogadas ambas como doctrinas incapaces de desarrollar algo más que un cuerpo teórico hipertrofiado sin ninguna progresión experimental12. Pero el mismo Lakatos reconocía que su interpretación del marxismo no era más que una hipótesis hasta que alguien lo demostrara mediante una reconstrucción historiográfica del marxismo aplicando su metodología. Para ello, habría que definir el contenido específico del «núcleo firme» y describir su evolución para demostrar que la senda del PIC marxista era claramente regresiva ${ }^{13}$.

De hecho, ha habido intentos de aceptar el reto de Lakatos y aplicar esta metodología al marxismo ${ }^{14}$, pero siguen siendo limitados porque las condiciones específicas del

11 Lakatos, 1989, op. cit., 15; 117.

12 Lakatos, Imre, "Lectures in Scientific Method", For and Against Method. Including Lakatos's Lectures on Scientific Method and the Lakatos-Feyerabend Correspondence, Chicago, The University of Chicago Press, 1999, 102.

13 Lakatos, 1999, op.cit., 106.

14 Blaug, Mark, A Methodological Appraisal of Marxian Economics, Amsterdam, North Holland, 1980; Bernstein, Howard R., "Marxist Historiography and the Methodology of Research Programs", History and Theory 20 (4), 1981, 424-449; Paramio, Ludolfo, “El materialismo histórico como programa de investigación”, Enrique Lamo de Espinosa y José Enrique Rodríguez Ibañez (eds.), Problemas de teoría social contemporánea, Madrid, CSIC, 1993, 551-590; Smith, Tony, “Marx's Theory of Social Forms and Lakato's Methodology of Scientific Research 
marxismo exigen adaptar -más que adoptar- la metodología de Lakatos a una tradición que no es estrictamente científica, al menos no en el sentido convencional del término. A continuación, examinaremos brevemente los dos mejores intentos de estudiar el marxismo como un PIC, el del sociólogo Michael Burawoy y el del politólogo Alex Callinicos.

\section{Burawoy compara a Trotsky con Skocpol}

El esfuerzo de Burawoy ${ }^{15}$ se destaca por su ambición y profundidad al comparar la teoría de las revoluciones propuesta por Theda Skocpol en su obra de 1979, Los Estados y las revoluciones sociales, con la temprana interpretación de Trotsky de la revolución en su obra Resultados y Perspectivas, de 1906. Burawoy asume que ambas teorías enfrentan una serie de anomalías, y la metodología de Lakatos permite discriminar cuál de ellas las resuelve mejor. Su conclusión es que la propuesta de Trotsky resultó, en su época, más exitosa que la de Skocpol.

Para Lakatos, dijimos, el «núcleo firme» de un PIC se plantea en términos ambiguos, sin pretensión de ser contrastado empíricamente. Precisamente porque su contraste llevaría a antinomias irresolubles, todo PIC desarrolla un «cinturón protector» de hipótesis auxiliares para protegerlo. Este «cinturón protector» se encarga de desarrollar la «heurística negativa», explicando por qué las anomalías no resultan lo suficientemente contundentes para derribar la apuesta originaria del PIC. Las teorías de alcance medio que componen el «cinturón protector» deberán ir reformulándose en el intento de sortear los problemas planteados por nuevas anomalías. Pero aquí un PIC puede hacer de la necesidad virtud si, al proteger su núcleo, consigue absorber lo que antes eran anomalías como nuevos fenómenos explicados. Es aquí donde más claramente se determina si un PIC tomará una senda progresiva o regresiva. En ocasiones, las anomalías son desestimadas por alguna hipótesis ad hoc, es decir, respuestas que realmente no mantienen una coherencia teórica con el PIC, sin aportar nada, y sin que puedan generalizarse a otras situaciones. En ese caso, el PIC corre serio riesgo de caer en una posición puramente defensiva, replegada, dogmática, buscando siempre excepciones a su propio planteamiento original. Cuando, por el contrario, la innovación teórica es capaz de convertir las anomalías en pruebas de nuevos fenómenos que anteriormente se habían pasado por alto, se abre la posibilidad de un desarrollo ulterior del PIC, alcanzando con éxito problemas que hasta el momento no se había planteado.

Al adoptar la metodología de los PICs al marxismo nos encontramos con la necesidad lógica de determinar cuál es su «núcleo firme». Esta tarea es esencial para cualquier PIC, ya que se compone de una pluralidad de teorías potencialmente contradictorias pero que, cuanto menos, comparten un mínimo denominador común que tratan de salvaguardar y desarrollar. Trotsky podía sostener una concepción de la revolución que no coincidiera con la de Karl Kautsky, pero ambos se reconocían como participantes de una misma comunidad o, específicamente, de un «campo marxista», al preocuparse por el desarrollo del mismo PIC, compartiendo los mismos postulados básicos

Programs", Fred Moseley y Martha Campbell (eds.), New Investigations of Marx's Method, Nueva York: Humanity Brooks, 1997, 76-97.

15 Burawoy, Michael, Dos métodos en pos de la ciencia: Skocpol vs Trotsky, Buenos Aires, Prometeo, 2003. 
fundamentales. Sin embargo, la comparación de Burawoy trata de dos teóricos pertenecientes a dos PICs alternativos, pero que disputan la explicación de los mismos fenómenos. Por lo tanto, el «núcleo firme» que Trotsky y Skocpol tratan de desarrollar no es el mismo16.

En cualquier caso, Burawoy se enfrenta con la necesidad de definir el contenido del «núcleo firme», y para ello existen dos estrategias. La primera consiste en establecerlo por convención. El investigador determina en qué medida una corriente o una escuela de pensamiento se encuentra dentro o fuera del PIC en función de su grado de aceptación del «núcleo firme» que el investigador ha asumido. En otro trabajo, Burawoy ${ }^{17}$ ha desarrollado esta estrategia, formalizando un «núcleo firme» para el marxismo en siete postulados a partir del famoso «Prólogo» de Marx de 185918. Pero parece necesario completar la estrategia de Burawoy con una segunda, que consistiría en reconstruir lo que en cada momento dentro del campo marxista se ha considerado como lo esencial e irrenunciable por sus propios participantes para poder considerarse miembro de esa comunidad. El «Prólogo» de 1859 fue, efectivamente, un texto canónico en el que se sintetizaba en unos pocos párrafos las líneas fundamentales de lo que fue denominado «Materialismo Histórico». Sin embargo, estas dos vías no se confunden. La segunda implica asumir que el núcleo es el resultado de un cierto consenso dentro del campo marxista, pero por su misma naturaleza este consenso es variable, por lo que el núcleo debiera cambiar con el tiempo. Son los mismos participantes los que deciden, dialógicamente y por su socialización intelectual, la frontera de quién está dentro o fuera del PIC marxista. Por lo tanto, resulta esencial conocer lo que en cada momento fue comprendido en el «campo marxista» como su esencia irrenunciable, pero, al mismo tiempo, es necesario establecer de antemano un recorte del objeto para que no baste la etiqueta «marxista» para considerar a un autor o una corriente parte del PIC.

Nos parece que es posible asumir una definición del «núcleo firme» del marxismo aún más sencilla que la plantea Burawoy recogiendo las tres ideas básicas con las que el mismo Marx en la famosa carta a Weydemeyer de 185219: 1) la existencia de las clases sociales como actores de carácter histórico, es decir, delimitado, pero con papel protagonista; 2) las relaciones antagónicas entre, por lo menos, algunas de estas clases, en función de relaciones de explotación del trabajo; y 3) un horizonte comunista en el que desaparecen las clases y, con ellas, el Estado y la explotación del hombre por el hombre.

Pero queda pendiente la segunda estrategia, no contemplada por Burawoy, que consiste en pensar el «núcleo firme» como algo más que estas sencillas ideas. Para relacionar los postulados fundamentales entre sí y permitir su desarrollo en teorías específicas de alcance más restringido, así como para apoyar la construcción de discursos políticos complejos, son necesarios otros postulados de carácter epistémico y metafísico. Así, Karl

\footnotetext{
16 Se podría objetar que es habitual considerar a Theda Skocpol como una autora, cuanto menos, cercana al marxismo. Lo importante aquí es que Buroway consideraba estar comparando dos PICs alternativos, y no dos alternativas dentro de un mismo PIC.

17 Burawoy, Michael, "Marxism as Science. Historical Challenges and Theoretical Growth", American Sociological Review 55, 1990, 775-793.

18 Marx, Karl, "Prólogo", Contribución a la crítica de la economía política, Madrid, Siglo XXI, 2008, 3-7.

19 Marx, Carlos y Federico Engels, Cartas sobre "El Capital", La Habana, Editora Política, 1976, 60-62.
} 
Kautsky asumía las tres ideas interpretándolas desde un progresismo social-darwiniano, con influencias de Herbert Spencer, mientras que desde el austro-marxismo Max Adler podría hacer lo mismo desde el neokantismo y, como tercer ejemplo, Georgy Lukács desde el hegelianismo. Los tres serían concepciones alternativas del «núcleo firme» de un mismo PIC, proponiendo elementos homólogos, pero no compatibles. De esta manera, llegamos a una nueva modificación del concepto de PIC de Lakatos para poder adaptarlo al marxismo: las controversias teóricas alcanzan también al núcleo del PIC sin que esas modificaciones impliquen un cuestionamiento del PIC mismo20.

\section{Callinicos reconstruye el trotskismo como un PIC}

Hemos comprobado que los protagonistas de una controversia pueden adoptar una retórica popperiana. Poco antes de morir, Trotsky planteó con esta retórica el equivalente a un «experimento crucial» que, a la manera del falsacionismo, serviría para falsar todo el programa revolucionario si no se cumplía.

Si el proletariado del mundo se muestra incapaz de cumplir la misión que le ha asignado el curso del desarrollo histórico, no nos quedará más remedio que reconocer que el programa socialista, basado en las contradicciones internas de la sociedad capitalista, es una utopía. Sería necesario, en ese caso elaborar un nuevo programa «mínimo», para la defensa de los intereses de los esclavos de la sociedad burocrática totalitaria. ¿Nos obligarán los datos objetivos a renunciar ya al proyecto de la revolución socialista? Este es el problema que se nos plantea. ${ }^{21}$

Como nuestra hipótesis es que los participantes del campo marxista se comportan como si desarrollara un PIC, esperamos que, mientras discuten la manera en que este o aquel acontecimiento desmiente o apoya a una teoría, en la práctica intentarán reelaborarla de tal manera que las anomalías sean absorbidas y dejen de cuestionar lo esencial de su propuesta. Hoy sabemos que el trotskismo, y el marxismo en general, sobrevivió a esa experiencia crucial que, según Trotsky, debía cuestionar todo el proyecto socialista. El otro notable ejemplo de aplicación de la metodología de Lakatos al marxismo es precisamente la historia del trotskismo de Callinicos 22 .

Tras la Segunda Guerra Mundial, el trotskismo se encontró con un dilema. Trotsky había sentenciado que el estalinismo sería un freno para la expansión de la revolución, a pesar de que la Unión Soviética (URSS) seguía conservando, a su parecer, un carácter esencialmente socialista, aunque deformado. Sin embargo, el socialismo soviético se

\footnotetext{
20 Alvin W. Gouldner (Los dos marxismos. Contradicciones y anomalías en el desarrollo de la teoría, Madrid, Alianza, 1983) trató de magnífica manera estas contradicciones en el mismo núcleo del marxismo. Si hemos dejado fuera este importante aporte es porque Gouldner no intentó aplicar Lakatos sino una versión matizada de Kuhn. Dejamos para otra ocasión el mostrar que, en el fondo, lo interesante de la propuesto de Gouldner está en ser, precisamente, una adaptación de Lakatos tal como estamos proponiendo en este artículo.

21 Trotsky, Leon, La URSS en guerra, 1939. Disponible en Marxist Internet Archive:

https://www.marxists.org/espanol/trotsky/1930s/edm1.htm

22 Callinicos, Alex, Trotskyism, Milton Keynes, Open University Press, 1990.
} 
extendió por Europa tras la guerra. Eso resultaba ser una anomalía importante para los trotskistas, ya que les obligaba a renunciar a una de las dos premisas de Trotsky. O bien el estalinismo no era incompatible con el avance de la revolución, o bien había que abandonar la identificación del socialismo con la propiedad estatal de los medios de producción tal como se daba en la URSS y en la Europa del Este. Resolver esta anomalía era de vital importancia porque, como vimos anteriormente, Trotsky había asumido una actitud popperiana según la cual una experiencia negativa debía llevar a refutar y desechar la teoría. Sin embargo, el trotskismo que le sucedió no asumió esa posición y se comportó como un PIC.

Callinicos diferencia varias posiciones de diversos autores y corrientes dentro del trotskismo ordenándolas bajo el rótulo de ortodoxias o herejías. Cada opción se ve obligada a reformular hipótesis y teorías para salvaguardar alguna tesis. Bajo la etiqueta de «ortodoxias», Callinicos sitúa a aquellos que mantuvieron que la URSS era un estado socialista, aunque burocrático y deformado. Para Callinicos, los ortodoxos cayeron en una tendencia regresiva al verse obligados a defender que los nuevos satélites de la URSS en la Europa del Este y China también eran socialistas, reconociendo así la capacidad del estalinismo para ejercer de agente revolucionario. Teorías como el «bonapartismo proletario» - para condenar políticamente lo que, al mismo tiempo, se definía como socialismo - son consideradas por Callinicos como hipótesis ad hoc que aletargaban la decadencia del proyecto.

Lo particular del marxismo como PIC es que su campo experimentación no es un laboratorio en el que todas las variables están bajo control, como en la ciencia convencional experimental. La experiencia de laboratorio exitosa es aquella en la que el científico consigue que las variables comprendidas por una teoría se comporten tal como ésta predice, mientras que se neutralizan las influencias de cualquier otra variable ajena a la teoría. Esto significa que el científico estudia un ambiente artificial creado por él mismo. En las Ciencias Sociales (CCSS) la situación es muy diferente porque la experiencia suele acontecer en una realidad social externa al investigador, quien ocupa el papel de observador y no creador de la situación estudiada. Es más, si la predicción de un economista influyese en la quiebra de una empresa, consideraríamos que se trata de una «contaminación» de la realidad que debería haberse evitado. Por eso, las predicciones en las CCSS suelen ser afirmaciones de acontecimientos que son externas al teórico en cuanto agente. En el caso del marxismo, por paradójico que parezca, la situación se acerca más a las condiciones de laboratorio que a las de observación externa de las CCSS.

De manera específica, el marxismo como PIC tiene su experiencia en un «campo de las luchas de clases» 23 , en el que por definición ningún actor tiene el control absoluto de las variables. No es ni una realidad externa al teórico ni un laboratorio en el que todas las variables están controladas. La pretensión del teórico marxista es plantear posibilidades de la transformación de ese campo de acuerdo con la teoría defendida. Desde su cuerpo teórico se estudian las lógicas sociales en curso, la acumulación de contradicciones en puntos nodales y las correlaciones de fuerza entre actores, de tal manera que una acción estratégica

${ }^{23}$ La expresión «campo de las luchas de clases» es tomada de Nicos Poulantzas (Poder político y clases sociales en el Estado capitalista, México D.F., Siglo XXI, 1974). 
tenga el máximo efecto transformador sobre el campo. El marxismo como PIC encuentra entonces su experiencia teórica exitosa en su praxis política, transformadora. De ahí la imposibilidad de separar teoría y praxis, pero no como un imperativo moral, sino como una necesidad intrínseca que se impone a su desarrollo como PIC. Por sus características, en el PIC marxista la praxis es el momento de realización de una producción teórica, de la misma manera que la producción teórica es la reflexión racional desde una praxis social.

Sin embargo, ni Burawoy ni Callinicos acaban de asumir este punto. Cuando Burawoy compara a Skocpol - una estudiosa de las revoluciones, pero no una revolucionaria - con Trotsky, no lo hace para examinar cuál de los dos demostró tener más capacidad transformadora, sino para mostrar qué predicciones fueron más acertadas. En este caso, la experiencia del PIC sería la experiencia externa al investigador, desarrollada por otros ${ }^{24}$. En el caso de Callinicos, al examinar las diferentes tendencias del trotskismo, sí asume que éstas tienen la pretensión de tener una acción transformadora. Para continuar con el ejemplo de los «ortodoxos», la suposición de que los nuevos estados de Europa del Este eran socialistas y que el estalinismo había demostrado capacidad para expandir el socialismo, llevó a algunas corrientes trotskistas a plantear la estrategia del «entrismo», es decir, la infiltración en los partidos comunistas y socialistas, en lugar de plantear una alternativa específicamente trotskista que la historia había demostrado como prescindible. Sin embargo, el mismo Callinicos reconoce que la influencia política del trotskismo fue tan débil que podemos desdeñarla. En consecuencia, surge el problema de que el PIC marxista necesita basar su criterio de validez en una praxis transformadora pero no consigue que ninguna de sus posiciones prácticas sea relevante. Si ninguna de las opciones debatidas consigue tener el más mínimo efecto real sobre el campo de las luchas de clases, entonces el PIC en su conjunto se vuelve regresivo, lo que lleva a Callinicos a explicar el sectarismo casi religioso de estas corrientes.

Examinados estos intentos, estamos ya en condiciones de especificar las particulares del marxismo de las que una adaptación de la metodología de Lakatos debe partir para ser exitosa. Primero, que las controversias en el campo marxista se dan también en lo que respecta a las articulaciones del «núcleo firme» y algunos de sus contenidos. Esto implica considerar al núcleo como resultado de una negociación y un consenso y, por eso, como variable en el tiempo, mientras que en un mismo momento pueden subsistir diversas interpretaciones. En segundo lugar, el PIC marxista se desarrolla a través de varias teorías regionales de alcance medio, y este desarrollo puede ser desigual. En algunas teorías regionales pueden darse avances notables mientras que en otras el PIC se encuentre estancado o en retroceso, al ser incapaz de solucionar las anomalías con las que se encuentra. En tercer lugar, para los marxistas una experiencia positiva es algo más que la predicción de hechos externos. La praxis política es la transformación del campo de las luchas de clases por ellos mismos, como agentes, asumiendo que el control de las variables no será total pero que, por otro lado, el resultado positivo es consecuencia de una acción racional consciente a

24 Podríamos decir que, en rigor, Burawoy (2003, op.cit.) tiene como principal objetivo no el de explicar el marxismo como un Programa de Investigación sino el de contrastar dos de lo que Lakatos (1989, op.cit.) denomina Programas Historiográficos, siendo uno de ellos la propia metodología de Lakatos, tomando el marxismo como ejemplo, y el otro la metodología inductivista a la que Skocpol afirma adscribir su teoría. 
partir de una reflexión teórica.

\section{El marxismo como PIC visto por sus clásicos.}

El filósofo argentino Enrique Dussel también se apoya en la metodología de Lakatos para conceptualizar la tradición marxista ${ }^{25}$, pero, además, aplica específicamente un criterio de demarcación que diferencia entre las ciencias «funcionales» y las «críticas», situando al marxismo de este segundo lado. Este criterio de demarcación contempla la praxis como transformación de unas condiciones de opresión, por lo que el marxismo considera su propia praxis revolucionaria como un criterio de validación interno y necesario para su propia existencia. Esto no sería más que una particularidad en la adaptación de los PICs de Lakatos al marxismo, que considera que el desarrollo teórico tiene en la praxis política su campo de experiencia, al campo de las luchas de clases.

No resulta evidente que todo lo que históricamente se ha considerado «marxismo» se haya comportado efectivamente como un PIC. Una investigación que se limite a fenómenos que le son externos - como quien estudiase desde el marxismo las luchas de clases en la Antigüedad - pertenecería igualmente a esta tradición de pensamiento, pero su dimensión práctica, imprescindible para considerarlo una ciencia «crítica», no estaría presente ${ }^{26}$. Pero incluso en un caso como este, de aportes puramente eruditos, lo teórico tiene efectos en las implicaciones prácticas de tal manera que podamos entenderlo como un aporte al PIC. Por ejemplo, una cuestión aparentemente tan ajena a la acción práctica del investigador como la de la tendencia inherente del capitalismo a su derrumbe, tenía importantes consecuencias en la estrategia política de las organizaciones obreras, como ha mostrado recientemente Caligaris ${ }^{27}$.

Sin embargo, en aras de la claridad, nos interesan ahora algunos ejemplos en los que, específicamente, los teóricos consideraron que la praxis era un momento interno de su teoría y, por ello, un elemento de su validación. Sería de esperar que clásicos del marxismo, como Gramsci, Luxemburgo, Kautsky o el propio Marx, interpretasen su propia experiencia en términos homólogos al de los PIC de Lakatos. Veremos brevemente algunos casos representativos que muestran que así fue.

\section{Antonio Gramsci}

Entre los más conocidos ejemplos está el del italiano Antonio Gramsci (1891-1937) al tratar la Revolución rusa de 1917. El triunfo de una revolución socialista en la periferia capitalista contradecía los pronósticos del Marx «histórico»y, por eso, se revelaba como una

\footnotetext{
25 Dussel, Enrique, Ética de la Liberación en la Edad de la Globalización y de la Exclusión, Madrid, Trotta, 1998.

26 Dussel incluso señala que de las ciencias «críticas» pueden surgir paradigmas «funcionales», es decir, legitimadores del statu quo. Eso sería lo opuesto al proyecto transformador del PIC marxista, pero es un posible camino para un PIC regresivo cada vez más impotente de transformar su realidad. Por eso, Dussel recurre al ejemplo del «marxismo soviético» como uno de estos desenlaces (Dussel,1998, op.cit., 451).

27 Caligaris, Gastón, “Revisitando el debate marxista sobre el 'derrumbe' del capitalismo. Una crítica metodológica", Izquierdas, 39, 2018, 182-208.
} 
«revolución en contra de El Capital» ${ }^{28}$. En términos muy similares a los de un PIC, Gramsci analiza la relación de los bolcheviques con la ortodoxia marxista contemporánea:

$\mathrm{Y}$, sin embargo, también en estos acontecimientos hay una fatalidad, y si los bolcheviques reniegan de algunas afirmaciones de El capital, no reniegan, en cambio, de su pensamiento inmanente, vivificador. No son «marxistas», y eso es todo; no [35] han levantado sobre las obras del maestro una doctrina exterior de afirmaciones dogmáticas e indiscutibles. Viven el pensamiento marxista, el que nunca muere, que es la continuación del pensamiento idealista italiano y alemán, y que en Marx se había contaminado con incrustaciones positivistas y naturalistas. ${ }^{29}$

Para Gramsci, los bolcheviques habían ido en contra de un desarrollo ortodoxo del PIC que se había demostrado infructuoso y, precisamente por ello, habían conservado lo esencial del proyecto, dándole un nuevo desarrollo progresivo. Con ese «no ser "marxista"», Gramsci estaba diciendo que los bolcheviques no se resignaron a asumir una teoría que había adquirido «incrustaciones positivistas y naturalistas». El marxismo sería una articulación compleja y estructurada de ideas, a veces contradictorias, y resultaba necesaria una actitud crítica dentro del propio marxismo. Es en ese sentido que "no son "marxistas"», ya que para mantenerse fieles a lo esencial del proyecto debían ir en contra de algunos de la ortodoxia, es decir, del consenso mayoritario en el campo marxista en ese momento.

Otra cuestión es el cómo se hizo y cuáles son los principios del «núcleo» y de las diversas teorías regionales que decidieron mantener y cuidar. Pero, por el momento, se trata de mostrar que la aplicación de Lakatos puede ser, ante todo, una excelente manera de sistematizar un conjunto de doctrinas y teorías que, necesariamente, guardan contradicciones y evolucionan hacia posiciones dispares. Esta metodología tiene, por tanto, una capacidad heurística importante al permitirnos entender la evolución de las controversias de una manera más profunda, e incluso juzgar qué salidas de los debates representaron petrificaciones degenerativas y cuáles propusieron auténticas contribuciones innovadoras.

\section{Rosa Luxemburgo}

Si Gramsci había pensado en términos de un PIC para dar cuenta del desarrollo progresivo del marxismo, unos años antes Rosa Luxemburgo (1871-1919) había hecho lo mismo para intentar explicar el estancamiento teórico. En un artículo titulado «Estancamiento y progreso del marxismo», de 190330, encontramos las breves reflexiones de Luxemburgo sobre el desarrollo de la teoría marxista hasta la fecha.

Luxemburgo comienza su artículo planteando una hipótesis: aquellos sistemas de ideas que están bien elaborados y cerrados desde el comienzo impiden su propio ulterior

28 Gramsci, Antonio, “La revolución contra El Capital”, Antología de Antonio Gramsci. Selección, traducción y notas de Manuel Sacristán, México D.F., Siglo XXI, 2005.

${ }^{29}$ Gramsci, 2005, op.cit., 34-35.

30 Luxemburgo, Rosa, "Estancamiento y progreso del marxismo", Obras escogidas. Tomo I, Bogotá, Editorial Pluma, 1976, 137-143. 
desarrollo. Pero desestima esta hipótesis, y sitúa la causa del estancamiento del marxismo no en lo teórico como sistema categorial, sino en la dificultad de desarrollar en el campo de las luchas de clases toda la heurística positiva del programa. Veamos por qué.

Luxemburgo creía que el marxismo no había avanzado desde que Engels publicara el Libro III de El Capital en 1894. Apenas algunas obras divulgativas habían aparecido, por lo que el PIC estaba detenido prácticamente donde lo dejaron sus fundadores. Pero de este estancamiento no se deduce que el marxismo fuera un sistema acabado por Marx y Engels, sin dejar margen para su desarrollo. Al contrario, apenas en cuestiones económicas el cuerpo teórico llegó tener una coherencia afianzada. Sin embargo, lo más valioso de todo, la «concepción materialista-dialéctica de la historia» era un «método de investigación» que ofrecía una heurística positiva para entender un mundo del que quedaba casi todo por investigar. Esto llevó a Luxemburgo a considerar que el aporte de Marx estaba infrautilizado.

La reflexión de Luxemburgo nos permite evitar explicaciones tan simplistas y psicologistas como que el marxismo necesitaba de nuevas "grandes cabezas». Lo que se propone Luxemburgo es explicar por qué faltaban esas "grandes cabezas», y no constatar su ausencia. La clave estaría en la ausencia de necesidades prácticas para formar esas grandes cabezas, ya que «Marx nos ha dejado mucho más de lo que resulta directamente esencial para la realización práctica de la lucha de clases»31. Llega entonces a la conclusión de que no existía una verdadera demanda práctica que exigiera mayor desarrollo teórico.

Habría más bien una especie de superávit teórico, ya que la teoría legada por Marx era tan rica que sobrepasaba con creces las necesidades prácticas de la clase, dada la correlación de fuerzas en el campo de las luchas de clases. Por el momento, las necesidades teóricas de las luchas de clases estaban ya resueltas con el Libro I de El Capital, porque el principal interés estaba en el origen secreto de la explotación, el plusvalor, y en demostrar la tendencia histórica hacia la socialización de los medios de producción. Los aportes de los Libros II y III no añadían nada de sustancial a esta justificación política, por imprescindibles que fuesen para dotar de coherencia teórica al sistema categorial de Marx ${ }^{32}$.

Las conclusiones de Luxemburgo son una mezcla de optimismo e ingenuidad. La virtud de su reflexión sobre la de Gramsci está en plantearnos más abiertamente una particularidad de esta metodología al aplicarla al marxismo: que los avances en la teoría deben explicarse en relación a las necesidades prácticas que se van presentando históricamente y, en cierta medida, de manera imprevista, contingente, permitiendo pensar el PIC como un proceso continuo de resolución de problemas prácticos que o bien encuentra directamente respuesta por el planeamiento teórico del PIC, o bien requiere reformularlo, ya sea en sus cinturones protectores o revisando su núcleo.

31 Luxemburgo, 1976, op.cit., 143.

32 Recordemos que solo con la categoría de «precio de producción» presentada en el libro III de El Capital se solucionaba el problema de la imposibilidad de vender las mercancías por su «valor», callejón sin salida al que llevaba el Libro I. 


\section{Karl Kautsky}

El gran teórico de la II Internacional y la socialdemocracia alemana, Karl Kautsky (18541938), asumió la tarea de sistematizar lo que vendría a ser el núcleo del PIC heredado de Marx y Engels y desarrollar las primeras teorías regionales de alcance medio ${ }^{33}$. En esta tarea se vio obligado a -como apuntaba Luxemburgo- desarrollar la teoría conforme las necesidades del campo de las luchas de clases lo exigía y, como decía Gramsci, también se veía obligado a ir en contra de Marx en ocasiones, precisamente para ser fiel al PIC antes que al dogma. Esto requería reconocer el contexto histórico cambiante con el que el PIC marxista en desarrollo iba encontrándose y, hasta cierto punto, ayudando a producir.

Hacia 1901, cuando Sombart estaba dando los últimos retoques a su obra, Kautsky ${ }^{34}$ se preguntaba explícitamente hasta qué punto el Manifiesto Comunista de 1848 seguía siendo un documento válido. Kautsky asumía que la estructura de clases había cambiado considerablemente en Europa, aunque consideraba que Rusia seguía asemejándose a las condiciones de Alemania en 1848. Con todo, en el nuevo contexto, la nueva estructura de clases tenía efectos en la estrategia revolucionaria. No era posible esperar un papel activo de la burguesía, como lo hicieron Marx y Engels, y el proletariado debía asumir que había quedado como la única clase políticamente revolucionaria. Esto implicaba una estrategia diferente a la «revolución permanente» defendida por Marx y Engels hacia 1850, y un paso hacia medios legales y pacíficos por los que el proletariado maduraría y acumularía fuerzas para la toma del poder. Esto no invalidaba, a ojos de Kautsky, lo esencial del Manifiesto, porque no cuestionaba el antagonismo de clase ni la necesidad del socialismo. Se trataba, simplemente, de la adaptación de lo esencial a las nuevas condiciones.

Ese texto fue publicado originariamente como prólogo a una nueva edición polaca del Manifiesto. Se entiende el cierto tono permisivo de un discípulo que no quiere contradecir públicamente a sus maestros, especialmente cuando ese discípulo es el gran representante de la ortodoxia dentro del campo marxista.

Sin embargo, en su correspondencia privada podemos ver a un Kautsky más críticamente posicionado. Unos años antes, en una carta al líder de la socialdemocracia austriaca Victor Adler (1852-1918), del 12 de noviembre de 1896, podemos comprobar toda la perspectiva de Kautsky en cuanto guardián de la ortodoxia del marxismo.

En su carta comienza posicionándose junto a Ede, es decir, el teórico socialdemócrata alemán Eduard Bernstein (1850-1932) -la gran figura del revisionismo en el campo marxista-, y contra Wilhelm Liebknecht (1826-1900) -el fiel representante de Marx y Engels durante décadas en Alemania-, en lo que se refiere a la «cuestión de Oriente», es decir, sobre el problema de las naciones y etnias en Europa bajo el control otomano. Critica a Liebknecht por escudarse detrás de la autoridad de Marx, sin asumir que las condiciones del momento ya no eran las de décadas antes. Liebknecht aparece como el continuador de la posición de Marx, pero una posición equivocada en un nuevo contexto. Por eso, Kautsky sentencia: «a

\footnotetext{
33 Haupt, Georges, "Marx y el marxismo", Eric J. Hobsbawm et al, Historia del marxismo. El marxismo en tiempos de Marx, Barcelona, Bruguera, 1980, 197-223.

34 Kautsky, Karl, “To What Extent is the Communist Manifesto Obsolete?”, Richard B. Day y Daniel Gaido (eds.), Witnesses to Permanent Revolution. The Documentary Record, Londres, Brill, 2009, 169-185.
} 
menudo ocurre que lo que antes era correcto después deja de serlo»35. Más adelante, Kautsky es aún más explícito: la posición de Marx sobre algunas cuestiones, como sobre Oriente, Polonia o el pueblo checo, se ha vuelto «insostenible». De ahí que Kautsky deduzca que sería «no-marxista» mantener la vieja posición de Marx cuando los «hechos» ya la han invalidado ${ }^{36}$.

Lo curioso es que Kautsky parecía situarse del lado de Bernstein, cuando Bernstein lo que pretendía era, precisamente, realizar una crítica del «núcleo» del marxismo, mientras que Kaustky se veía a sí mismo como un guardián del «núcleo» que debía desechar las partes del «cinturón protector» que ya no servían para una heurística positiva satisfactoria. En realidad, es solo acerca de estas cuestiones específicas que Kautsky coincide con Bernstein. Si leyéramos la carta completa a Adler, veríamos que comienza, precisamente, criticando a Bernstein por el planteamiento general de sus artículos que posteriormente serían publicados como los Problemas del socialismo, principal obra del revisionismo marxista. Por lo tanto, en lo que se refiere al «núcleo» del marxismo, Kautsky se enfrenta con Bernstein, pero en lo que se refiere a las teorías regionales de alcance medio, ambos pueden coincidir contra aquellos que mantienen las mismas posiciones que Marx mantuvo.

\section{Karl Marx}

Lo que estamos sugiriendo es que la historia del marxismo no puede reducirse a una historia de sus ideas. Con la metodología de Lakatos podemos plantear el potencial heurístico (negativo y positivo) del marxismo -en las relaciones mutuas de lo teórico con la praxiscomo el hilo para reconstruir esta tradición. Tampoco el pensamiento de Marx evolucionó como la superación abstracta de un sistema teórico dentro de los propios confines de la teoría, sino que, por el contrario, era el resultado de una actividad política con necesidades prácticas concretas en configuraciones históricas particulares.

Las obras de juventud de Marx son, precisamente, un proceso de ruptura con la filosofía especulativa de los jóvenes hegelianos, antiguos camaradas duramente criticados por su posición pasiva ante la realidad histórica, consecuencia de una pretendida teoría pura que se limitaba a ser la negación abstracta de la irracionalidad de la sociedad. Pero será en su breve autobiografía intelectual del «Prólogo» de 1859 en la que Marx explique cómo llega desde la filosofía hegeliana a estudiar y criticar la Economía Política burguesa.

A primera vista, su recorrido parece el desarrollo lógico de una serie de ideas específicamente teóricas. Marx nos explica que, por su disputa con Hegel, había situado a la «sociedad civil» como el centro de su preocupación, y no como un producto del Estado. De

\footnotetext{
35 "As regards the main issue, the Oriental question, I am wholly in agreement with Ede and felt that his article was all the more significant because Liebknecht's quite incredible stance on the question entrenches itself behind the authority of Marx. I am afraid Liebknecht still stands on all points exactly where he stood at the time of the Crimean War. But what was right then may well be wrong now, and usually is." Citado en Tudor, Henry y Tudor, J. M. (eds.), Marxism and Social Democracy. The Revisionist Debate 1896-1898, Cambridge, Cambridge University Press, 1988, 82.

36 "I'm afraid I hold the view, both on the Oriental and on the Polish questions, that the old Marxist line has become untenable, and so has Marx's attitude to the Czechs. It would be completely un-Marxlike to close one's eyes to the facts and persist in the old Marxist view." Idem.
} 
ahí que Marx se planteara el análisis de su «anatomía», pero pronto llegó a la conclusión de que este análisis no podía hacerse desde la Filosofía, ni siquiera desde el Derecho, lo que le llevó a emprender el estudio de la Economía Política. Hasta aquí, todo el recorrido es una concatenación lógica de ideas. Pero este recorrido teórico no se hace independientemente del campo de las luchas de clases, y el propio Marx especifica que fue por su labor periodística al acabar su periodo universitario que se encontró con «en el compromiso de tener que opinar acerca de lo que han dado en llamarse intereses materiales» ${ }^{37}$. Durante su etapa de periodismo militante en la Gaceta Renana (1842-1843) Marx se ve obligado a confrontar por primera vez los intereses materiales. La filosofía hegeliana no podía aportarle gran cosa en cuestiones donde estos intereses materiales premiaban, y es esta constricción práctica la que le empujará a buscar su superación.

Pero dejemos ese dato aparcado durante un momento, y tratemos, en paralelo, una segunda línea de razonamiento. En su propia reconstrucción, Engels ${ }^{38}$ nos dice que fue $L a$ esencia del cristianismo, de Ludwig Feuerbach (1804-1872), la obra que «pulverizó de golpe la contradicción, restaurando de nuevo el trono, sin más ambages, el materialismo» ${ }^{39}$. El impacto que causó su lectura fue tal que «todos nos convertimos en feuerbachianos» 40 . Esta reconstrucción de Engels sigue planteando la evolución del pensamiento como un recorrido lógico que se da exclusivamente en el plano teórico y en el que la superación de una idea lleva necesariamente a otra. Pero si atendemos a la reconstrucción biográfica de Marx de Franz Mehring41, encontraremos un relato algo distinto.

La virtud de una reconstrucción biográfica es que, por definición, no es una reconstrucción lógica, sino histórica. Según Mehring, no fue La esencia del cristianismo de Feuerbach, publicada en 1841, la que impactó realmente a Marx, sino las Tesis provisionales para la reforma de la filosofía, publicadas en 1843, justo en el momento en el que Marx renuncia a su trabajo de editor de la Gaceta del Rin y decide abandonar Prusia para dirigirse a París para poder continuar sin censura con su labor crítico-periodística, es decir, justo en el momento en «que la filosofía de Hegel se había demostrado incapaz para resolver los problemas materiales que se le plantearan en la Gaceta del Rin»42. Desde la perspectiva de Mehring, el salto teórico a la crítica de Hegel desde y con Feuerbach no es algo que sucediese exclusivamente en el ámbito de lo teórico, de los sistemas lógicos de conceptos, con relaciones que se revelarían como no-necesarias, como arbitrarias, y por eso como susceptibles de crítica y superación. Más bien, lo que hay es un agotamiento progresivo de lo que un sistema teórico, por muy coherente que sea, nos permite realizar prácticamente, y ese es el momento decisivo de la contradicción y el mayor acicate para la crítica y reformulación de un cuerpo teórico. Por eso Mehring señala este episodio y remarca que Engels «desdibuja un poco las relaciones y los vínculos espirituales entre Feuerbach y

\footnotetext{
37 Marx, 2008, op.cit., 3.

38 Engels, Friedrich, "Ludwing Feuerbach y el fin de la filosofía clásica alemana". Obras escogidas de Karl Marx y Friedrich Engels, tomo III, Moscú, Progreso.

39 Ibid.,362.

40 Idem.

${ }^{41}$ Mehring, Franz, Karl Marx: historia de su vida, Buenos Aires, Marat, 2013.

42 Ibid., 76
} 
Marx»43, ya que, aunque Marx había leído La esencia del cristianismo y en esta obra ya estaban expuestas claramente las ideas de Feuerbach, «en los trabajos publicados por Marx en la Gaceta del Rin no se perciben todavía las influencias de Feuerbach»44.

Lo que nos asegura Mehring con esto es que esa relación teórica entre sistemas de ideas -la filosofía de Hegel, la crítica de Feuerbach y el sistema en construcción en el pensamiento de Marx- solo se entiende a partir de este contexto de necesidades prácticas concretas en las que Marx, desde su militancia periodística, necesitaba tomar partido en medio del campo de las luchas de clases de su tiempo. Castro-Gómez ${ }^{45}$ lo plantea en términos comparables cuando afirma que la reelaboración teórica de Marx en este periodo no puede entenderse como una ruptura epistemológica, sino como una evolución en los límites de un pensamiento todavía republicano. Marx estaría adoptando un «republicanismo plebeyo», en el que los desposeídos en su materialidad ocupaban ahora el papel universal que, en el «republicanismo abstracto», jugaba el Estado.

Desde esta perspectiva adquieren sentido los siguientes pasos de Marx. Primero, propuso a su admirado Feuerbach participar en su nuevo proyecto desde el exilio -los futuros Anales Franco-Alemanes - con una crítica al filósofo Schelling, con gran prestigio entre los socialistas franceses por aquel tiempo. Para él mismo, Marx se proponía realizar una crítica a la Filosofía del Derecho de Hegel ${ }^{46}$. Esa crítica era homóloga a la que Feuerbach ya había realizado, pero ya no en el terreno de la filosofía de la naturaleza o de la religión, sino en la filosofía del derecho. Por eso, en su «Introducción para la Crítica de la Filosofía del Derecho de Hegel», Marx comienza diciendo que «Para Alemania, en resumen, la crítica de la religión está terminada y la crítica de la religión es la premisa de toda crítica» 47 . El programa, para Marx, ya había agotado uno de los pasos abiertos por su heurística positiva, y debía continuar desarrollándose en nuevas teorías de alcance medio.

Esta manera de reconstruir la evolución del pensamiento de Marx es importante porque permite, por ejemplo, evitar una interpretación que caiga en el pragmatismo, es decir, que considere que el criterio de verdad se reduce a la efectividad práctica de una idea, sin importar el contenido teórico-lógico de esa idea ${ }^{48}$. En ese caso estaríamos relacionando

43 Ibid., 75.

44 Idem.

45 Castro-Gómez, Santiago, “Marx y el republicanismo plebeyo”, Nómadas, 48, 2018, 13-32.

46 Feuerbach rechazaría la oferta en una carta fechada el 25 de octubre de 1843, al considerar «que no respondería a una necesidad científica, sino simplemente a una conveniencia política» (Feuerbach, Ludwig, "Carta a Karl Marx. 25 octubre 1843", Karl Marx y Friedrich Engels, Obras fundamentales. Escritos de juventud. Tomo I, México D.F., Fondo de Cultura Económica, 1982, 694). Más bien, la aplicación de Lakatos muestra que la necesidad científica para Marx se plantea también en el ámbito de la praxis y no exclusivamente en el de la coherencia de los sistemas de ideas.

47 Marx, Karl, “Introducción para la Crítica de la Filosofía del Derecho de Hegel”, G.W.F. Hegel, Filosofía del derecho, Buenos Aires, Claridad, 1968, 7.

48 Otro ejemplo que podríamos haber usado para este propósito es el primer rechazo, la posterior aceptación, y la ulterior superación crítica de Marx de la teoría ricardiana del valor. Mandel (La formación del pensamiento económico de Marx. De 1843 a la redacción de El capital: estudio genético, México D.F., Siglo XXI, 1974) explica que autores como T.S. Edmonds, W. Thompson, J. Bray probaban que la interpretación de Ricardo sobre el valor y los precios podía resultar políticamente subversiva. Pero para Mandel esto no significa que Marx y Engels adoptaran una lectura ricardiana por mero pragmatismo (u oportunismo). Para que Marx pudiera aprovechar 
teoría-praxis como si fueran dos elementos distintos y discretos, que se articulan mecánicamente. La dificultad está, precisamente, en percibir la mediación de uno en otro, es decir, de entender la praxis como un momento de la teoría, y la teoría como un momento de la praxis. En otras palabras, un avance en el PIC marxista no consiste en recurrir a una «idea» porque ésta demuestre tener un efecto satisfactorio en la praxis política, sino que consiste en la producción de una idea como traslación de la práctica al campo teórico, de la misma manera que el desarrollo en el campo de las luchas de clases solo es posible desde alguna lectura teórica, por muy implícita que esta esté. Y Lakatos tendría que concordar en este punto porque, para él, «una proposición fáctica no es sino una clase especial de proposición teórica» 49 .

\section{Conclusión \\ Las claves para una adaptación de la propuesta de Lakatos a la historiografía del marxismo.}

La adaptación que proponemos de la metodología de Lakatos a la historiografía de las controversias en el marxismo tiene la virtud de reintegrar la praxis política como un elemento del debate teórico mismo, evitando caer en aquellas reconstrucciones que lo limitan a una sucesión de teorías alternativas o complementarias, pero cuyo criterio de validez estaría en su coherencia interna, y no en la heurística positiva que se realiza en la praxis política.

No por ello nuestra adaptación reduce la teoría a un simple reflejo mecánico de la praxis o a la simple representación de fuerzas y tendencias sociales en la conciencia de los actores. Lo teórico tiene una consistencia que le es propia y debe entenderse por su coherencia interna en cuanto sistema categorial. Su relación con la praxis debe permitirnos explicar por qué tal articulación teórica surge en un momento y un lugar determinado y por qué ganó o perdió legitimidad dentro del campo marxista, sin por ello considerar que lo teórico es una mera racionalización a posteriori.

En este artículo nos hemos limitado a mostrar la pertinencia de pensar en una adaptación de Lakatos habida cuenta que sus propios protagonistas parecen haber discutido sobre el desarrollo del marxismo desde términos muy similares a los de esta metodología. Para ulteriores investigaciones que se centren en controversias teóricas específicas, la adaptación propuesta consiste en separar analíticamente el PIC marxista en tres tipos de espacios que, en el análisis de cada controversia concreta, deberán ser relacionados.

El primero es la comunidad en la que se discute -el campo marxista-, con unas fronteras que determinan quién pertenece a él y quién no. Este es el espacio relacional en el que las controversias teóricas surgen cuando los marxistas reconocen anomalías que deben ser discutidas. En algunos casos, las anomalías son entendidas como síntomas de un problema cuya solución debe fundamentarse en alguna modificación o innovación en la teoría. Esta metodología nos permite rastrear las diferentes posiciones con respecto a las

el potencial revolucionario de esa teoría tuvo que someterla a una estricta crítica teórica.

49 Lakatos, 1989, op.cit., 27. 
anomalías que se adoptan en el campo. Los ortodoxos, los heterodoxos, los dogmáticos o los revisionistas son etiquetas tradicionalmente usadas en el marxismo para denominar las posiciones en relación con el núcleo del PIC y las teorías regionales que lo desarrollan. Los ortodoxos tienden a negar que las anomalías cuestionen el núcleo mismo del PIC. Los dogmáticos, directamente niegan la existencia de tales anomalías. Los revisionistas encuentran el problema en el núcleo del PIC y proponen modificaciones del mismo. Los heterodoxos pretenden respetar el núcleo proponiendo teorías originales para su cinturón protector. Estas posiciones se enfrentan en diversas arenas dentro del campo que son, ellas mismas, las formas en las que el espacio relacional toma cuerpo. La controversia permanece hasta que la se cierra con una nueva ortodoxia que convierte lo que antes eran anomalías en fenómenos esperados dentro del renovado cuerpo teórico. La adaptación de Lakatos abre una interesante perspectiva de investigación para reconstruir esas arenas más o menos institucionalizadas - tales como congresos o revistas - en las que las disputas teóricas se resuelven prácticamente.

El surgimiento de anomalías imprevistas y, por eso, incomprendidas teóricamente, pueden deberse a las dinámicas en un segundo tipo de espacio: las formaciones sociales históricas en sí mismas, con sus estructuras sociales, políticas y económicas específicas. Cuando el PIC marxista se desarrolla en el tiempo y se expande geográficamente, va encontrando situaciones crecientemente dispares y novedosas. En nuevas regiones del mundo o en nuevas dimensiones de la sociedad antes no exploradas, nuevos fenómenos cuestionan la ortodoxia en vigor. Por lo tanto, tenemos un campo marxista en el que se discuten teóricamente las anomalías que van surgiendo en unas formaciones sociales heterogéneas, complejas y cambiantes. En sus momentos regresivos, el PIC marxista se ha enfrentado con fenómenos incomprensibles, pero en sus periodos progresivos, el PIC marxista ha encontrado en estos nuevos escenarios un contexto propicio para proponer nuevas estrategias.

Ahora bien, si el campo marxista se dedicase exclusivamente a analizar ese segundo espacio desde la exterioridad intelectual del primer espacio, estaríamos en el mismo caso que cualquier teoría social cuyo cometido fuera explicar el mundo. Lo específico del marxismo es la emergencia de un tercer espacio, un campo en el que los desarrollos teóricos se vuelven experiencias prácticas: el campo de las luchas de clases. Si las CCSS hacen predicciones del comportamiento de sujetos y objetos que le son externos, el marxismo hace «apuestas» sobre lo que, como fuerza social, es capaz de lograr en un contexto histórico determinado. Si las Ciencias Naturales (CCNN) transforman las condiciones naturales en ambientes artificiales de laboratorio, el marxismo trata de transformar el campo de las luchas de clases en órdenes sociales de mayor racionalidad. Esa es la especificidad del marxismo.

Por tanto, la evolución del PIC a través de sus controversias viene marcada por el desenlace de diferentes tipos de acontecimientos en espacios analíticamente diferenciables, sin que se limiten específicamente a la batalla de ideas dentro del campo marxista. Algunos de estos acontecimientos tienen un carácter político e histórico en el campo de las luchas de clases tales como huelgas, campañas o rebeliones. Además, impactan acontecimientos propios del mundo histórico sobre el que se proyectaban esas luchas, como cambios culturales, demográficos, o económicos, de los que surgen anomalías y necesidad de 
proponer nuevas teorías de alcance medio. Otros son acontecimientos propios del campo marxista y pueden llegar a tener importantes efectos en la reinterpretación teórica del proyecto, tales como la publicación de una obra inédita -piénsese en el impacto que tuvo la publicación de los Manuscritos Económicos-Filosóficos o los Grundrisse de Marx ya en el S.XX, que modifica la concepción que los marxistas sostenían hasta la fecha de su propio «núcleo».

Tomar en cuenta las interrelaciones teórico-prácticas de las dinámicas de estos tres espacios analíticamente diferenciables es lo que permite adaptar la metodología de Lakatos a una tradición teórico-práctica como el marxismo.

\section{Referencias bibliográficas}

Bandy, Alex, Chocolate and Chess. Unlocking Lakatos, Budapest, Akadémiai Kiadó, 2010.

Bernstein, Howard R., "Marxist Historiography and the Methodology of Research Programs", History and Theory 20 (4), 1981, 424-449.

Blaug, Mark, A Methodological Appraisal of Marxian Economics, Amsterdam, North Holland, 1980.

Burawoy, Michael, "Marxism as Science. Historical Challenges and Theoretical Growth", American Sociological Review 55, 1990, 775-793.

Burawoy, Michael, Dos métodos en pos de la ciencia: Skocpol vs Trotsky, Buenos Aires, Prometeo, 2003.

Caligaris, Gastón, "Revisitando el debate marxista sobre el 'derrumbe' del capitalismo. Una crítica metodológica”, Izquierdas, 39, 2018,182-208.

Callinicos, Alex, Trotskyism, Milton Keynes, Open University Press, 1990.

Castro-Gómez, Santiago, “Marx y el republicanismo plebeyo”, Nómadas, 48, 2018, 13-32.

Dusek, Val, "Lakatos between Marxism and the Hungarian Heuristic Tradition", Studies in East European Thought 67:1, 2015, 61-73.

Dussel, Enrique, Ética de la Liberación en la Edad de la Globalización y de la Exclusión, Madrid, Trotta, 1998.

Engels, Friedrich, "Ludwing Feuerbach y el fin de la filosofía clásica alemana”, Karl Marx y Friedrich Engels, Obras escogidas. Tomo III, Moscú, Progreso, 1978, 353-395.

Feuerbach, Ludwig, "Carta a Karl Marx. 25 octubre 1843", Karl Marx y Friedrich Engels, Obras fundamentales. Escritos de juventud. Tomo I, México D.F., Fondo de Cultura Económica, 1982, 694.

Fleck, Ludwik, La génesis y el desarrollo de un hecho científico, Madrid, Alianza Editorial, 1986. Caligaris, Gastón, "Revisitando el debate marxista sobre el 'derrumbe' del capitalismo. Una crítica metodológica", Izquierdas, 39, 2018, 182-208.

Goldmann, Lucien, El hombre y lo absoluto, Barcelona, Península, 1968.

Gouldner, Alvin W., Los dos marxismos. Contradicciones y anomalías en el desarrollo de la teoría, Madrid, Alianza, 1983.

Gramsci, Antonio, "La revolución contra El Capital", Antología de Antonio Gramsci. Selección, traducción y notas de Manuel Sacristán, México D.F., Siglo XXI, 2005.

Hanson, Norwood R., Patterns of Discovery: An Inquiry into the Conceptual Foundations of Science, Cambridge, Cambridge University Press, 1958. 
Haupt, Georges, "Marx y el marxismo", Eric J. Hobsbawm et al, Historia del marxismo. El marxismo en tiempos de Marx, Barcelona, Bruguera, 1980, 197-223.

Kadvany, John, Imre Lakatos and the Guises of Reason, Londres, Duke University Press, 2001. Kautsky, Karl, "To What Extent is the Communist Manifesto Obsolete?", Richard B. Day y Daniel Gaido (eds.), Witnesses to Permanent Revolution. The Documentary Record, Londres, Brill, 2009, 169-185.

Koyré, Alexandre, Estudios galileanos, Madrid, Siglo XXI, 1980.

Kuhn, Thomas S., La estructura de las revoluciones científicas, Madrid, Fondo de Cultura Económica, 2001.

Lakatos, Imre, La metodología de los programas de investigación científica, Madrid, Alianza Editorial, 1989.

Lakatos, Imre, "Lectures in Scientific Method", For and Against Method. Including Lakatos's Lectures on Scientific Method and the Lakatos-Feyerabend Correspondence, Chicago, The University of Chicago Press, 1999, 19-112.

Luxemburgo, Rosa, "Estancamiento y progreso del marxismo", Obras escogidas. Tomo I, con introducción de Mary-Alice Waters, Bogotá, Editorial Pluma, 1976, 137-143.

Mandel, Ernest, La formación del pensamiento económico de Marx. De 1843 a la redacción de El capital: estudio genético, México D.F., Siglo XXI, 1974.

Marx, Carlos y Federico Engels, Cartas sobre "El Capital", La Habana, Editora Política, 1976.

Marx, Karl, "Intoducción para la Crítica de la Filosofía del Derecho de Hegel”, Georg Wilhelm

Friedrich Hegel, Filosofía del derecho, Buenos Aires, Claridad, 1968, 7-22.

Marx, Karl, "Prólogo", Contribución a la crítica de la economía política, Madrid, Siglo XXI, 2008, 3-7.

Mehring, Franz, Karl Marx: historia de su vida, Buenos Aires, Marat, 2013.

Paramio, Ludolfo, "El materialismo histórico como programa de investigación", Enrique Lamo de Espinosa y José Enrique Rodríguez Ibañez (eds.), Problemas de teoría social contemporánea, Madrid, CSIC, 1993, 551-590.

Popper, Karl, La lógica de la investigación científica, Madrid, Edición Tecnos, 1980.

Popper, Karl, Conjeturas y refutaciones: el desarrollo del conocimiento científico, Barcelona, Paidós, 1983.

Poulantzas, Nicos, Poder político y clases sociales en el Estado capitalista, México D.F., Siglo XXI, 1974.

Ropolyi, Laszlo, "Lukács and Lakatos", Kampis, György, Kvasz, Ladislav, Stoeltzner, Michael (eds.), Appraising Lakatos, Londres, Springer, 2002, 303-338.

Smith, Tony, "Marx's Theory of Social Forms and Lakato's Methodology of Scientific Research Programs". Fred Moseley y Martha Campbell (eds.), New Investigations of Marx's Method, Nueva York: Humanity Brooks, 1997, 76-97.

Trotsky, Leon, La URSS en guerra, 1939. Disponible en Marxist Internet Archive. https://www.marxists.org/espanol/trotsky/1930s/edm1.htm

Trotsky, Leon, El pensamiento vivo de Karl Marx, Buenos Aires, Editorial Losada, 1943.

Tudor, Henry y Tudor, J. M. (eds.), Marxism and Social Democracy. The Revisionist Debate 18961898, Cambridge, Cambridge University Press, 1988. 